\title{
Numerical study on the deformation of soil stratum and vertical wells with gas hydrate dissociation
}

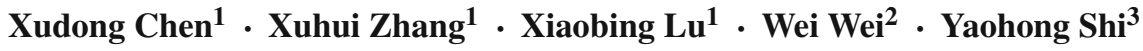

Received: 24 September 2015 / Revised: 12 April 2016 / Accepted: 9 May 2016 / Published online: 20 July 2016

(C) The Chinese Society of Theoretical and Applied Mechanics; Institute of Mechanics, Chinese Academy of Sciences and Springer-Verlag Berlin Heidelberg 2016

\begin{abstract}
Gas hydrate (GH) dissociates owing to thermal injection or pressure reduction from the well in gas/oil or GH exploitation. GH dissociation leads to, for example, decreases in soil strength, engineering failures such as wellbore instabilities, and marine landslides. The FLAC3D software was used to analyze the deformation of the soil stratum and vertical wells with GH dissociation. The effects of Young's modulus, internal friction angle, cohesion of the GH layer after dissociation, and the thickness of the GH layer on the deformation of soils were studied. It is shown that the maximum displacement in the whole soil stratum occurs at the interface between the GH layer and the overlayer. The deformation of the soil stratum and wells increases with decreases in the modulus, internal friction angle, and cohesion after GH dissociation. The increase in thickness of the GH layer enlarges the deformation of the soil stratum and wells with GH dissociation. The hydrostatic pressure increases the settlement of the soil stratum, while constraining horizontal displacement. The interaction between two wells becomes significant when the affected zone around each well exceeds half the length of the GH dissociation zone.
\end{abstract}

Xuhui Zhang

zhangxuhui@imech.ac.cn

1 Institute of Mechanics, Chinese Academy of Sciences, Beijing 100190, China

2 Research Institute of Petroleum Exploration and Development-Langfang, Langfang 065007, China

3 Marine Environmental and Engineering Geological Survey, Guangzhou Marine Geological Survey, Guangzhou 510075, China
Keywords Gas hydrate $\cdot$ Dissociation $\cdot$ FLAC3D · Soil stratum $\cdot$ Well

\section{Introduction}

A hydrate is a crystalline icelike solid composed of guest molecules such as methane, carbon dioxide, tetrahydrofuran, sulfur dioxide, and water molecules. Gas hydrate $(\mathrm{GH})$ is distributed extensively in permafrost and marine strata under sufficiently high pressure and low temperature conditions $[1,2]$.

Most previous studies focused on the exploitation of $\mathrm{GH}$ $[3,4]$. However, GH dissociation reduces the strength of hydrate-bearing soils (HBS) and leads to hazards such as marine landslides on a large engineering scale and instabilities of exploitation wells on a local small scale [5-10]. The Storegga slide in Norway [11,12], the Cape Fear slide on the east coast of the USA, the landslide on the continental shelf of West Africa [13,14], and other landslides [15] in marine conditions were regarded as the result of GH dissociation. The 2010 Deepwater Horizon explosion in the Gulf of Mexico might have been caused by GH dissociation since the drilling rig was in the stratum where the pressure and temperature are suitable for hydrate formation [16]. However, the deformation of the soil stratum and vertical wells with GH dissociation is poorly understood.

Wang et al. [17] investigated the responses of a well in the soil stratum with GH dissociation. That study focused on the effects of the degree of GH dissociation on well deformation. Cai et al [18]. proposed a model to describe the thermo-hydro-mechanical coupling behavior of unsaturated soils. Sultan et al. [19] presented a method to simulate excess pore pressure using a state equation under no fluid dis- 
sipation and no-volume change of soils. Then gas-dissolved water filled the pores of the soil skeleton, leading to geological hazards such as fractures or even gas outburst under unloading conditions. Iwai et al. [20] simulated the coupled behaviors of heat transfer, phase transformation of hydrate to gas and water, soil deformation, and seepage and presented the main factors for ground stability during hydrate dissociation. Zhang et al. [10,21] studied the layer fracture and gas outburst in the stratum during/after $\mathrm{GH}$ dissociation using both experimental and theoretical methods and presented the mechanisms of excess pore fluid pressure-induced soil failures. However, it is still not clear what the critical condition of soil failure is during $\mathrm{GH}$ dissociation with a rapid dissipation of fluids in the pores, which is important for the evaluation of $\mathrm{GH}$ exploitation.

This paper aims to examine the deformation of the soil stratum and vertical wells during $\mathrm{GH}$ dissociation. The development of deformation in the soil stratum and vertical wells with $\mathrm{GH}$ dissociation was simulated using FLAC3D software, decoupled with heat transfer and fluid seepage. The elastic-plastic constitutive model and the Mohr-Coulomb criterion were adopted to describe the deformation and failure behaviors of soil. The effects of modulus, internal friction angle, cohesion, and thickness of the GH layer on the deformation were investigated.

\section{Introduction of numerical model}

GH dissociation starts and expands from a vertical well (with hot fluid in the well as the heat source). Methane gas and water are released and assumed to drain rapidly, while the soil strength of the dissociation zone decreases significantly. Under the weight of the overlayer and hydrate layer following $\mathrm{GH}$ dissociation, soil deformations develop. Plastic failure occurs when the dissociation zone expands to a critical value, then soil failures, such as marine slides, will occur. In this problem, three main physical effects are involved, i.e., heat transfer with GH dissociation, fluid seepage, and soil deformations and failures. The ratios of the three characteristic times are approximately $10^{9}: 10^{5}: 1$, and the three physical processes can be solved by the decoupling method. The significance of decoupling is that the slowest heat transfer, the fluid seepage, and the most rapid soil deformation can be solved in order of the time sequence. The expansion of the hydrate dissociation zone and the fluid seepage are two slow physical effects, and analytical solutions are obtained [10]. Here, the problem is simplified such that the soil deformation and failure complete instantaneously under the given $\mathrm{GH}$ dissociation zone, pore fluid pressure, and stress status.

FLAC3D is a kind of numerical software developed on the basis of continuum mechanics for geotechnical engineering problems. Using a rapid Lagrange difference method, the deformation and failure of soil, especially a large deformation, can be analyzed, even coupling with the physical processes of heat transfer and multiphase flow in porous media. The applicability of FLAC3D was validated by centrifugal test on the stratum instability of a 90 m slope during hydrate dissociation [22]. Hence, numerical simulations on stratum instabilities during hydrate dissociation were conducted using FLAC3D on large engineering scales.

Here the responses of the HBS were simulated with the length of the dissociation zone expanded from 50 to $250 \mathrm{~m}$. The responses of the soils were affected by the relative size of the dissociation zone, the relative thickness of the $\mathrm{GH}$ layer, the relative modulus, and the shear strength coefficients of the GH layer following dissociation to before dissociation [9,22]. Here, decoupled analysis was conducted, and the deformation and soil failure were simulated following complete hydrate dissociation. The present constitutive model describes the soil mechanical behaviors of hydrate-bearing sediments and sediments following hydrate dissociation. An elastic-plastic stress-strain relationship was adopted as the constitutive model in the numerical simulations. The shear strength was described by the Mohr-Coulomb yielding criterion. The elastic deformation was considered till the soil shear strength was reached. The elastic modulus and shear strength of the soil layers (hydrate layer and overlayer) were obtained in triaxial tests of hydrate-bearing sediments before and after hydrate dissociation, and geological and geotechnical parameters were adopted referring to the drilling and well logging results of the Dongsha hydrate area in the South China Sea (Table 1) [22,23]. In the following simulation, three factorseffects of modulus, strength coefficients (internal friction angle and cohesion), and thickness of GH layer-were investigated.

A sketch of the numerical model is shown in Fig. 1. The size of the stratum was set as length $\times$ width $=1000 \mathrm{~m} \times$ $1000 \mathrm{~m}$, the thickness of the GH layer was $25 \mathrm{~m}$, the thickness of the overlayer was $200 \mathrm{~m}$, and the slope was $15^{\circ}$. The

Table 1 Soil parameters

\begin{tabular}{lllll}
\hline Parameter & $\begin{array}{l}\text { Elastic modulus } \\
E(\mathrm{MPa})\end{array}$ & $\begin{array}{l}\text { Density } \rho \\
\left(\mathrm{g} / \mathrm{cm}^{3}\right)\end{array}$ & $\begin{array}{l}\text { Poisson's } \\
\text { ratio } v\end{array}$ & $\begin{array}{l}\text { Cohesion } \\
c(\mathrm{~Pa})\end{array}$ \\
\hline Overlayer & 40 & 2 & 0.2 & 38 \\
GH layer before dissociation & 136 & 1.98 & 0.3 & 1000 \\
GH layer after dissociation & 70 & 1.92 & 0.25 & 5.33 \\
\hline
\end{tabular}




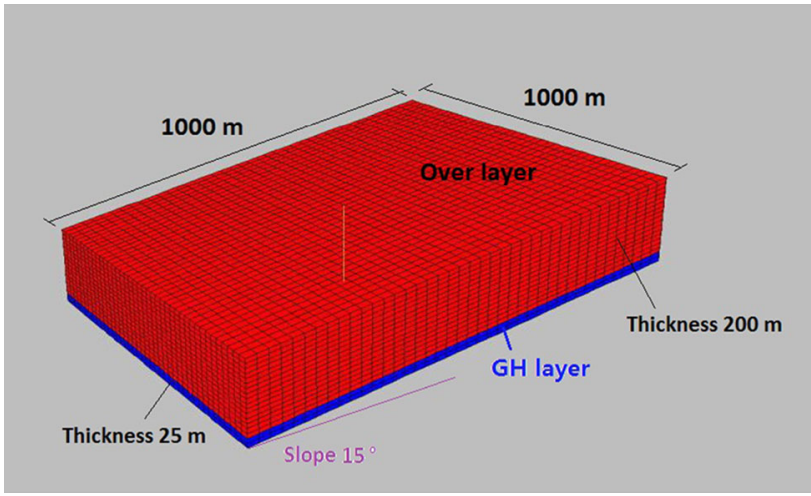

Fig. 1 Sketch of numerical model

bottom of the overlayer was glued to the GH layer, keeping the deformation continuous. The boundary conditions of the soil stratum were set as follows: the bottom was fully fixed, the lateral boundaries were normally fixed, and the surface was free. A well of size $\varphi \times t=0.4 \mathrm{~m} \times 0.02 \mathrm{~m}$ was set in the center of the model, passing through the soil layers vertically. The elastic modulus $E$ of the well was $2 \times 10^{11}$ $\mathrm{Pa}$, and the Poisson's ratio $v$ was 0.3 . The well was regarded as a pile unit in FLAC3D to describe the deformation and interaction with the soil.

\section{Results and discussions}

\subsection{Development of deformation under different lengths of dissociation zone}

\subsubsection{Development of settlement zone}

Figure 2 shows the affected area of soil settlement when the length of the dissociation zone is $200 \mathrm{~m}$. With the expansion

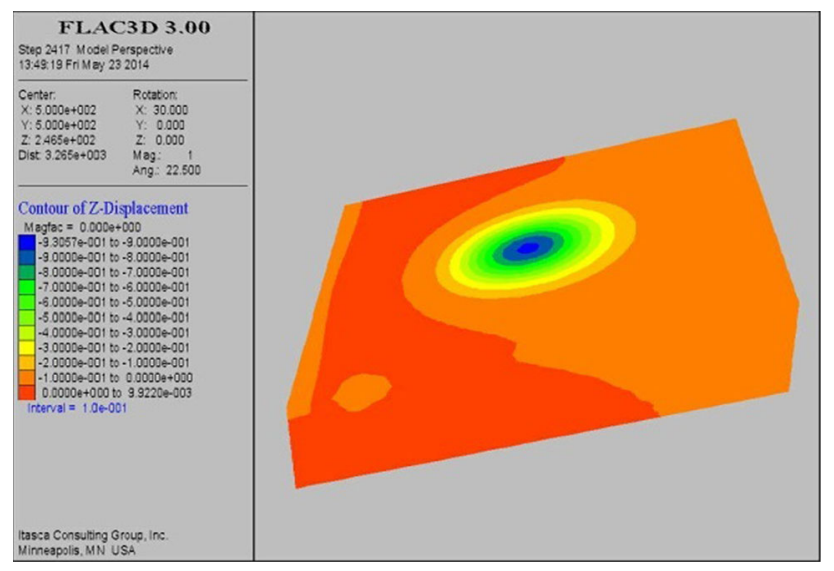

Fig. 2 (Color online) The affected zone of the GH dissociation zone, the settlement zone expands in an approximately symmetrical way.

The largest settlement is located at the surface of the GH layer. The maximum settlement at the overlayer's surface is located near the well and increases linearly with the expansion of the dissociation zone (Fig. 3). The reason for this is that the strength of the GH layer supporting the overlayer decreases with GH dissociation. The soil settles and moves horizontally along the slope under gravity. The affected zone expands with the expansion of the dissociation zone (Fig. 4).

It should be noted that in the following figures, $A$ indicates the length of the affected zone, $D_{1}$ the size of the dissociation zone, $H$ the thickness of the GH layer, $h$ the thickness of the overlayer, $w_{\max }$ the maximum horizontal displacement of the well, $S_{z}$ the settlement at the surface of the overlayer, $S_{x}$ the horizontal displacement of soils, $S_{z \max }$ the
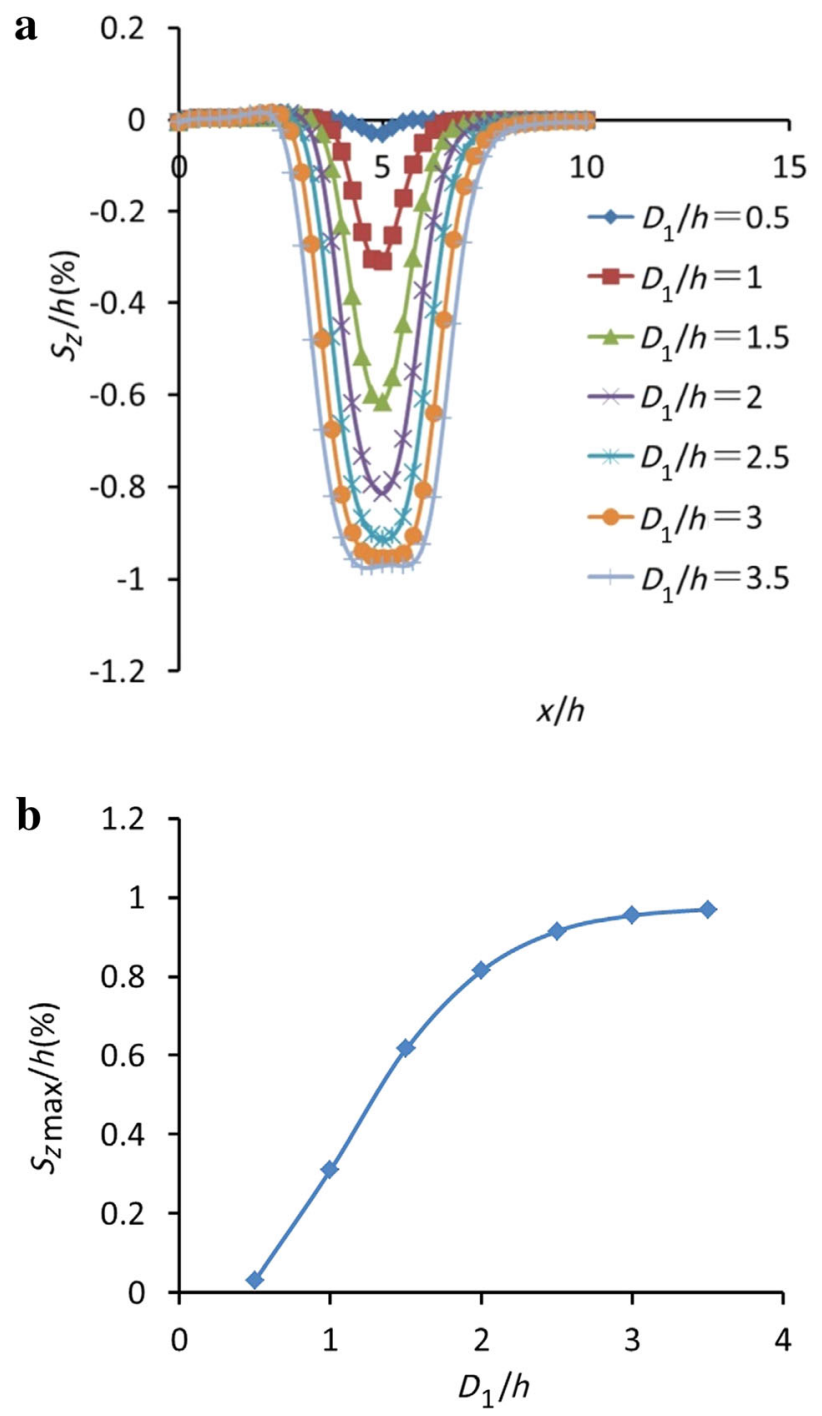

Fig. 3 Development of settlement with expansion of dissociation zone. a Settlement at surface. b Maximum settlement at surface 


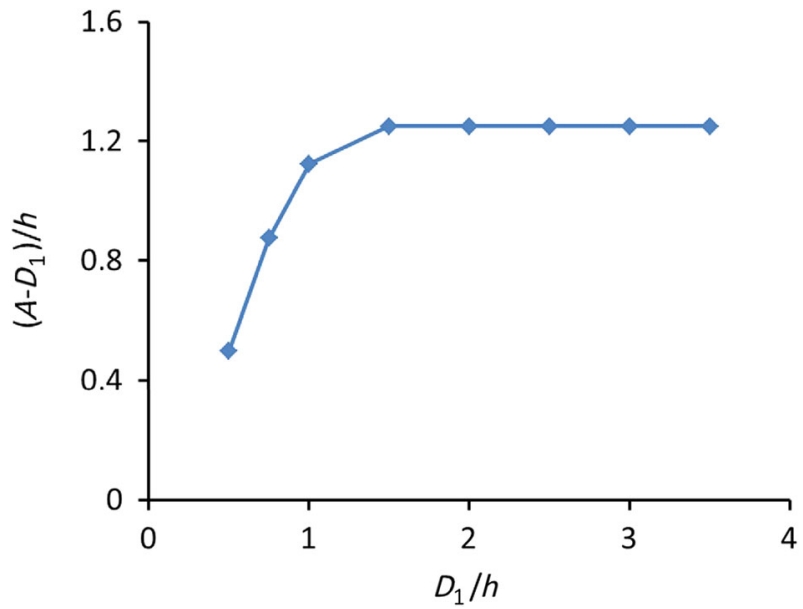

Fig. 4 Development of affected zone with expansion of dissociation zone

maximum settlement at the surface of the overlayer, $z$ the vertical position, and $x$ the horizontal position. The affected zone is defined as the zone where the ratio of settlement at the surface to the thickness of the overlayer exceeds $0.05 \%(s / h \geqslant$ $0.05 \%)$.

\subsubsection{Horizontal displacement}

Figure 5 shows the horizontal displacement of soils under a length of dissociation zone of $200 \mathrm{~m}$. The data at the vertical sections of $300,400,450,550,600$, and $700 \mathrm{~m}$ from the toe of the slope, respectively, are adopted for discussion. The direction of the horizontal displacements in the overlayer is different from the dissociation centerline (coincident with the well) $(x=500 \mathrm{~m})$. Downward from the centerline, the soils move upward to the centerline, and the horizontal displacement increases with the decrease in the distance from the centerline, while above the centerline the soils move down-

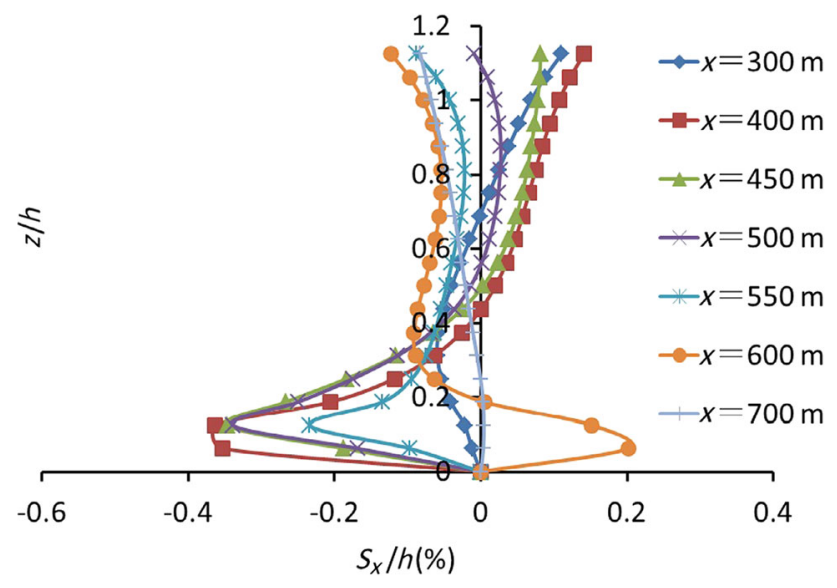

Fig. 5 Development of horizontal displacement of soil stratum ward to the centerline. In the overlayer, soil settlement occurs with softening in the GH dissociation zone, pulling the soils to move toward the centerline. Under the constraint of an undissociated hydrate zone and lateral sides, the soils move toward the centerline, forming a funnel-shaped settlement zone, while in the GH layer, the settlement of the overlayer pushes the soil away from the centerline, mostly toward the toe of the slope. The settlement along the slope and squeezing of the soil leads to changes in the horizontal displacement along the depth.

\subsubsection{Displacement of vertical well}

The well is supported by the soils. The deformation of the well increases with the increase in the displacement of the soils. In Fig. 6a, the largest well's displacement for each length of the dissociation zone is located at the interface between the overlayer and the GH layer and increases with the expansion of the dissociation zone. The main reason for this is that the displacement of the vertical well is caused

a
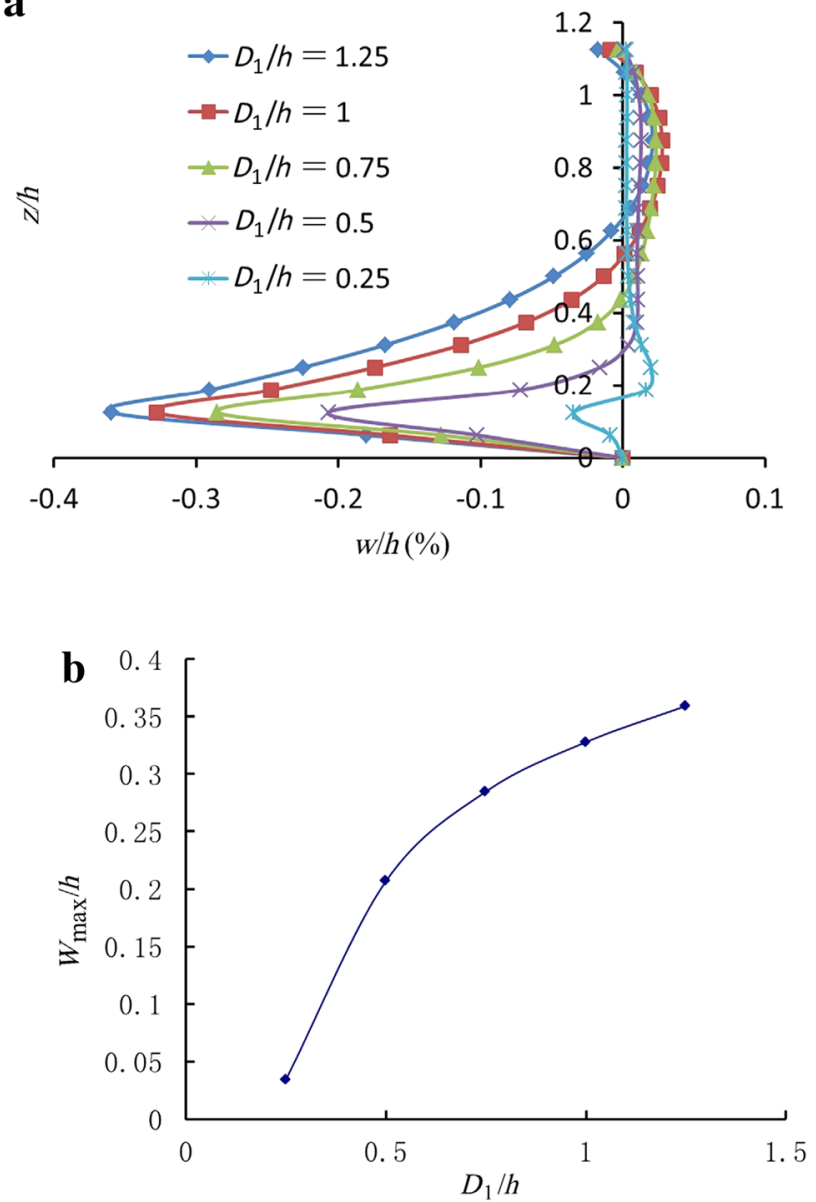

Fig. 6 Horizontal displacement of well under different lengths of GH dissociation zone. a In vertical section. b Largest displacement 
Table 2 Cases for numerical simulation

\begin{tabular}{lllll}
\hline No. & Modulus $(\mathrm{MPa})$ & Cohesion $(\mathrm{Pa})$ & Internal friction angle $\varphi\left({ }^{\circ}\right)$ & 25 \\
\hline 1 & 70 & $1 \times 10^{5}$ & 5.33 & \\
2 & 35 & & & \\
3 & 105 & $1 \times 10^{5}$ & 0 & 25 \\
4 & 70 & & 2.68 & \\
5 & & $1 \times 10^{5}$ & 15 & 50 \\
6 & 70 & & 5.33 & 75 \\
7 & & $1 \times 10^{6}$ & 5.33 & 25 \\
10 & 70 & & & \\
\hline
\end{tabular}

by the soil deformation. Hence, the trend of the horizontal displacement of the well along the depth is consistent with the soil (Fig. 5). The larger stiffness of the well leads to differences in the magnitude. The displacement is zero at the bottom owing to the fixed boundary condition, while the largest displacement is located at the surface of the GH layer. Owing to the inherent stiffness of the well and continuous elastic deformation, the horizontal displacement is upward. The inherent stiffness and the interaction force between the well and soil leads to changes in the deformation of the well along the depth. Figure $6 \mathrm{~b}$ shows the largest horizontal displacements with different lengths of the dissociation zone. The magnitude of the changes decreases when the dissociation zone exceeds $100 \mathrm{~m}$. This is because the supporting effect of the lateral sides on the well is reduced when the dissociation zone is smaller than $100 \mathrm{~m}$.

\subsection{Effects of main factors on displacements of soil layer and well}

The effects of the main factors, such as the modulus, internal friction angle, cohesion, and thickness of the GH layer, on the displacement of the soil layer and well are examined. The results obtained when the dissociation zone is under $200 \mathrm{~m}$ long are discussed. The cases in the numerical simulation are listed in Table 2.

\subsubsection{Effect of modulus}

Three moduli are considered here: 105, 70, and $35 \mathrm{MPa}$. The settlement increases with the decrease in the modulus. The maximum settlement decreases $30 \%$ and increases $80 \%$ when the modulus increases $50 \%$ and decreases $50 \%$, respectively (Figs. $7 \mathrm{a}$ and $7 \mathrm{~b}$ ).

The size of the affected zone decreases with increases in the modulus (Fig. 7c). In addition, the horizontal displacement of the well develops with the modulus of the $\mathrm{GH}$ layer (Fig. 7d). The largest horizontal displacement of the well increases $110 \%$ when the modulus decreases $50 \%$. The well's displacement is caused by the displacement in the over layer and the GH layer (Fig. 7e).

\subsubsection{Effect of cohesion}

Figure 8 presents the effect of the cohesion of the GH layer on the deformation of the soil layer and well. The deformation of the soil and well increases with the expansion of the dissociation zone and the decrease in cohesion; the change is slight even if the cohesion (much less than $10^{6} \mathrm{~Pa}$ ) changes tenfold. This is because the term $\sigma \tan \varphi$ is on the order of $10^{6}$, so the effect of the cohesion is smaller by at least one order of magnitude.

\subsubsection{Effect of internal friction angle}

The larger the internal friction angle, the greater the strength of the soil layer. Thus, the deformation is limited for a large internal friction angle. Once the internal friction angle drops below $4^{\circ}$, the deformation of both the soil layer and the well increases quite rapidly (Figs. 9a and 9b). This indicates that the strength of the soil layer is controlled by the internal friction angle in these cases. When the internal friction angle is smaller than $4^{\circ}$, the failure zone increases rapidly with decreases in the internal friction angle. While most soils are in an elastic state, the deformation changes slowly with a decrease in the internal friction angle when it is greater than $4^{\circ}$. The plastic deformation zone and the affected zone increase with decreases in the internal friction angle (Fig. 9c).

\subsubsection{Effect of GH thickness}

Three GH thicknesses are adopted here: 25,50 , and $75 \mathrm{~m}$ $(H / h=1 / 8, H / h=2 / 8$, and $H / h=3 / 8)$. Both the affected zone and the settlement increase with increases in the GH layer's thickness. The affected zone is in a linear relationship with the thickness, while the settlement increases slowly with increases in the thickness. The settlement of the $\mathrm{GH}$ layer is linear to the thickness after dissociation in the 

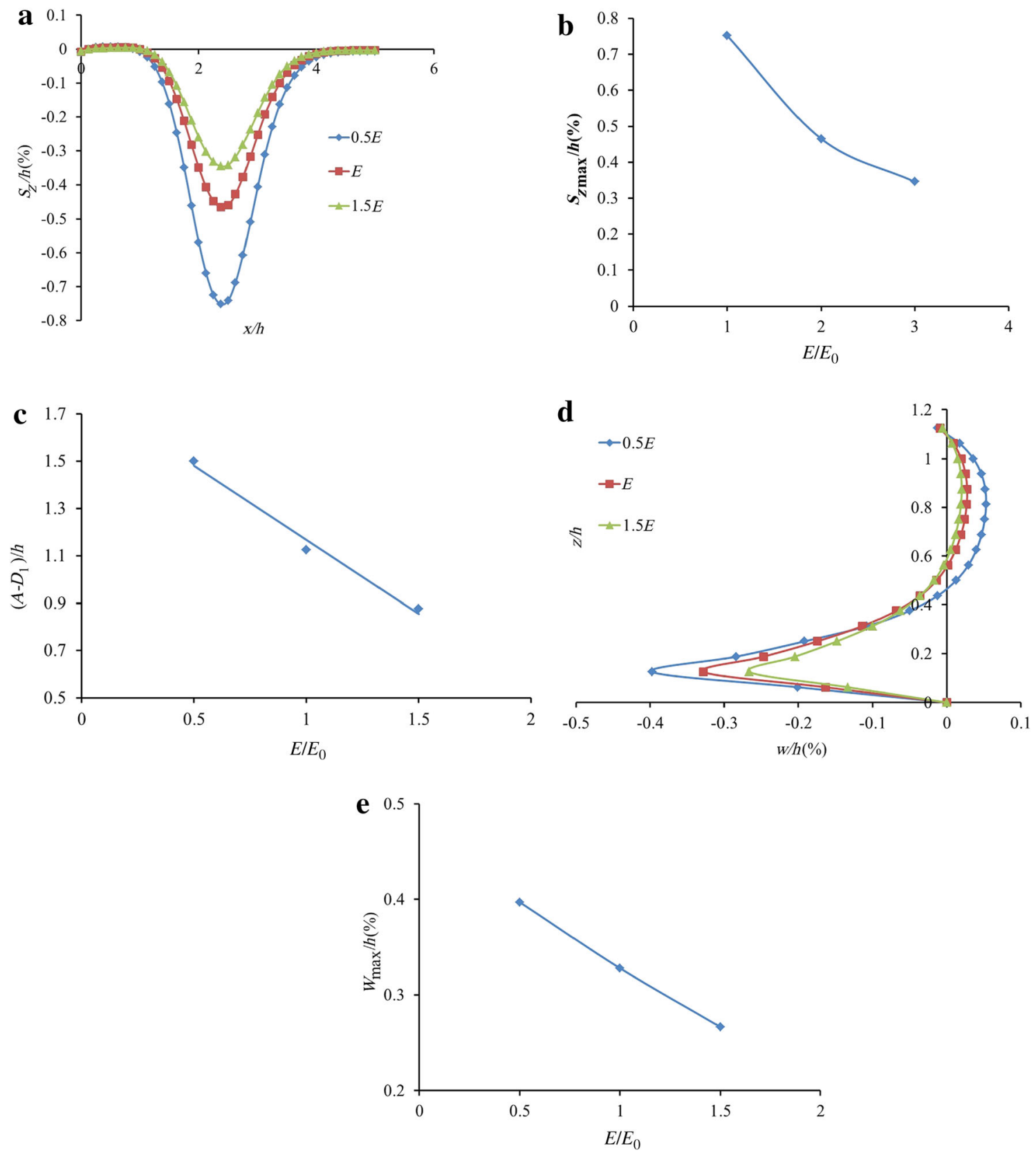

Fig. 7 Effects of modulus on deformation of soil stratum and well. a Distribution of settlement at surface of overlayer. b Largest settlement. $\mathbf{c}$ Size of affected zone. d Horizontal deformation of well. e Largest horizontal deformation of well. $E_{0}$ in plots $\mathbf{b}, \mathbf{c}, \mathbf{e}$ is $70 \mathrm{MPa}$

estimation of the consolidation (Fig. 10). The overlayer can be regarded as a deep beam overlying the GH layer, and it deforms linearly with the deformation of the GH layer. The affected zone in the nondissociation zone is approximately constant with increases in the dissociation zone. Deformation is mainly related to the strength coefficients (internal friction angle and cohesion) and the thickness of the overlayer using the limit equilibrium method. In the first stage, this zone increases with the dissociation zone because the failure zone in the overlayer is relatively small, and elastic deformation is dominant in a small dissociation zone.
The deformation of the well increases with the expansion of the dissociation zone (Fig. 11). When the ratio of the length of the dissociation zone to the thickness of the over layer is less than 0.5, the maximum deformation increases more for the dimensionless thickness of the GH layer (the ratio of thickness of the GH layer to the thickness of the over layer) $1 / 8$ than $2 / 8$ and $3 / 8$. The change of the well's deformation becomes slow with the expansion of the dissociation zone when the dimensionless thickness of the GH layer is less than 1/8 (Fig. 11). The supporting effect of the over layer to the well is dominant when the dimensionless thickness 

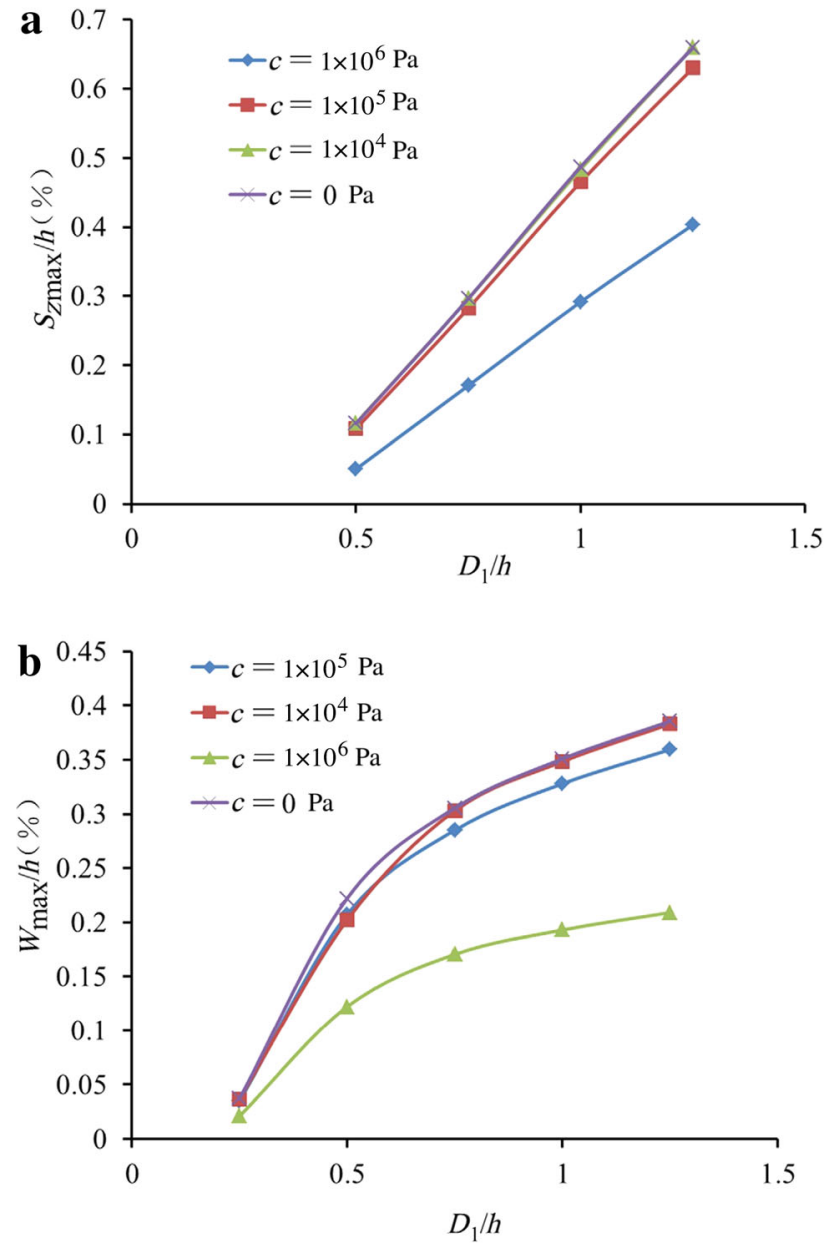

Fig. 8 Effects of cohesion of GH layer on deformations of soils and well. a Maximum settlement at surface of overlayer. b Maximum deformation

of the GH layer $H / h$ is small. The displacement of well is small similar to that of the GH layer in the small thickness. With the increase of $H / h$, the bearing force of GH layer to the well increases and the displacement of the GH layer increases with the expansion of the GH dissociation.

\subsubsection{Effect of well interaction}

The effects amongst soils and two wells were studied. The distance between the two wells was $200 \mathrm{~m}$. The deformation with two wells is the same as that with single well at the length of dissociation zone less than $50 \mathrm{~m}$. Only when the length of dissociation zone is over $150 \mathrm{~m}$, the deformation of the two wells is much different from the case of a single well. At a small length of dissociation zone, the dissociation zone around the two wells and the two affected zone for each dissociation zone are independent. With the expansion of dissociation zone, the affected zones and dissociation zones connected, thus the bearing force of the un-dissociated zone
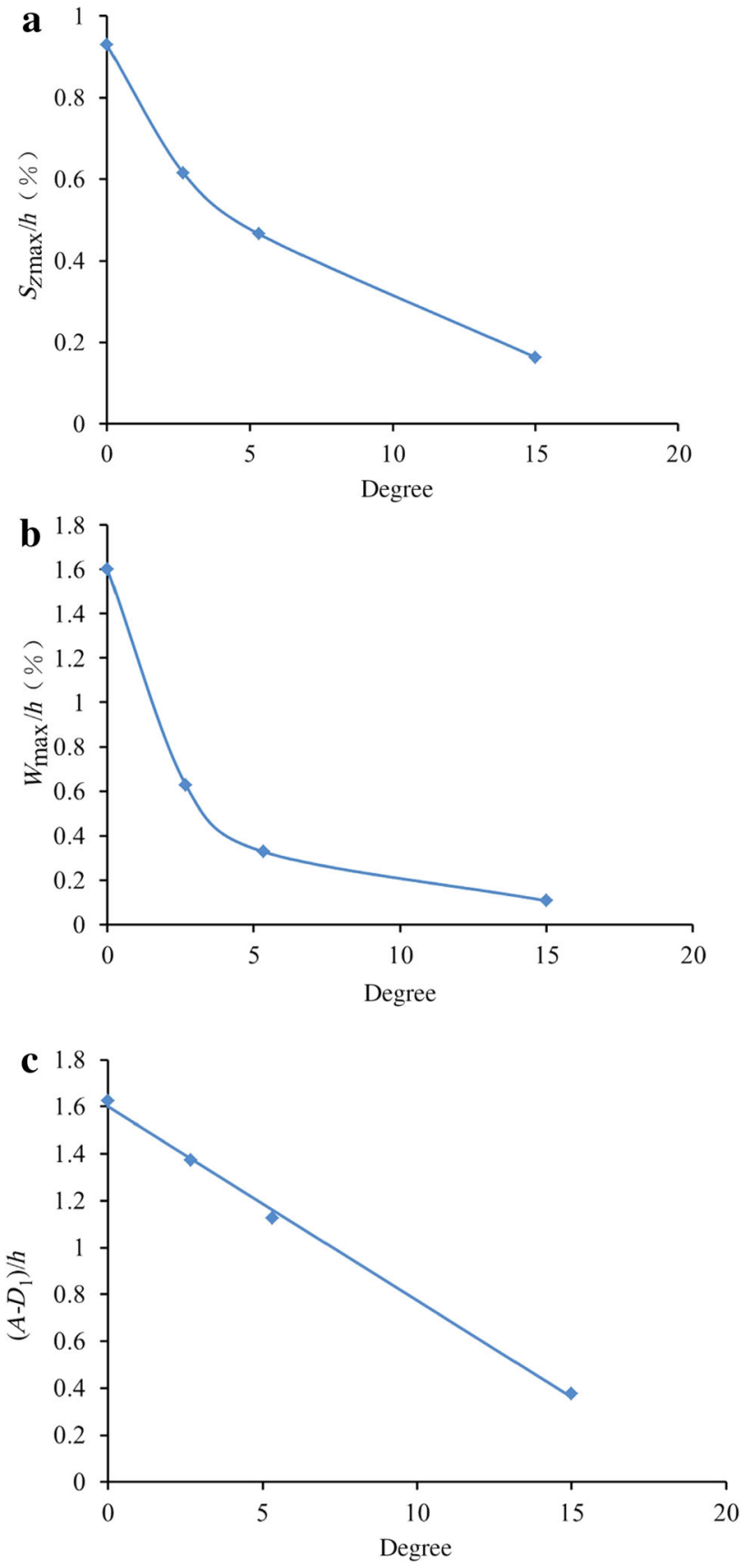

Fig. 9 Deformations of soil stratum and well under different internal friction angles. a Largest settlement at surface. b Largest horizontal deformation of well. c Development of affected zone

to the wells becomes weaker, and the deformation becomes larger than that case of a single well. Figure 12 presents the deformation of the two wells and a comparison with the deformation under a single well condition.

\subsubsection{Effect of water depth}

Three water depths were adopted, 500, 1000, and $1500 \mathrm{~m}$, to study the effects of hydrostatic pressure. Generally, in 

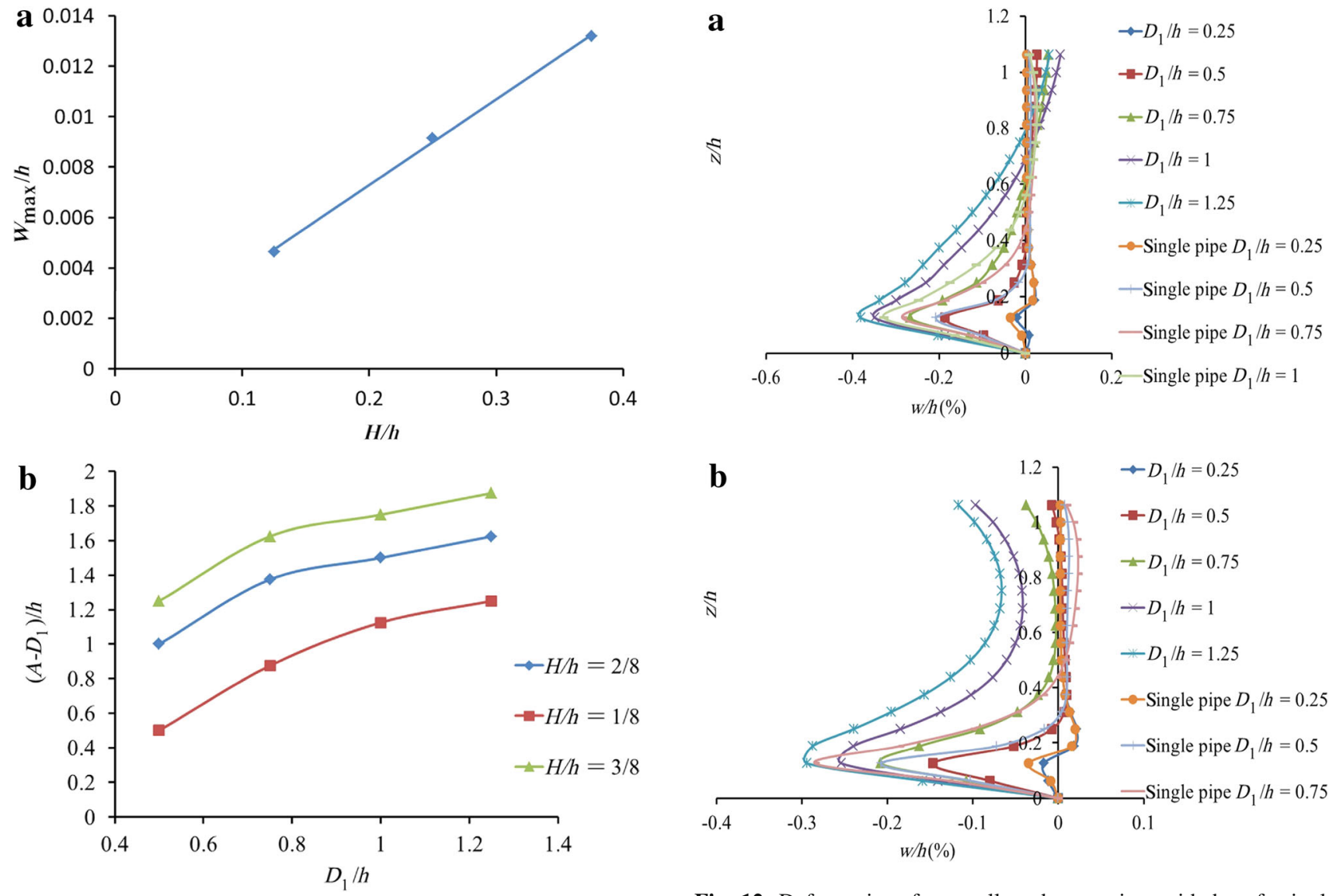

Fig. 10 Effects of GH layer's thickness on soil deformation. a Maximum deformation at surface. $\mathbf{b}$ Changes in affected zone

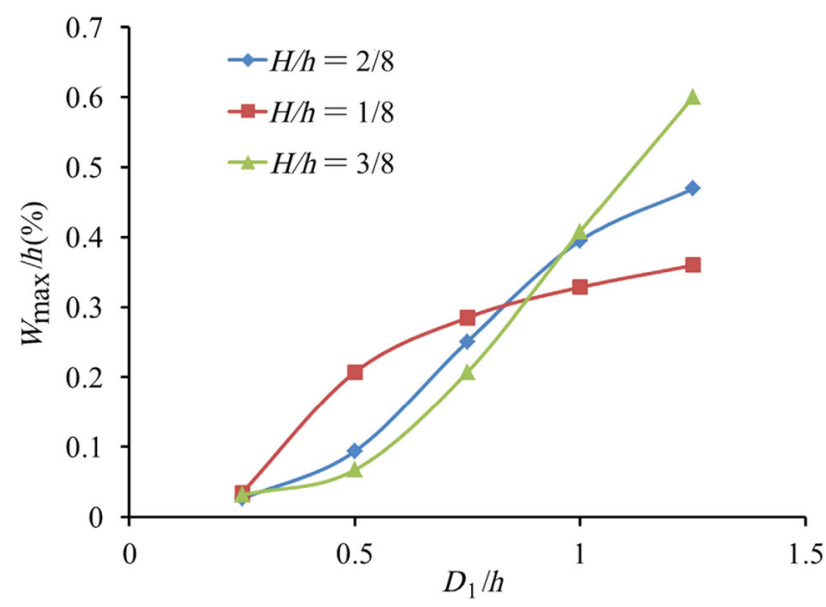

Fig. 11 Effects of the GH layer's thickness on the well's maximum horizontal displacement

hydrate formation, the overlayer is impermeable. Here, the increase in the water depth increases the total stress of the soil, while the pore fluid pressure in the hydrate layer is assumed to be irrelevant to the water depth, and the stiffness of the well is unchanged in the numerical simulation. Hence, in Fig. 13,

Fig. 12 Deformation of two wells and comparison with that of a single well condition. a At a distance from slope to $400 \mathrm{~m}$. b At a distance from slope to $600 \mathrm{~m}$

both the settlement and the affected zone increase with water depth. The reason for this is that the increase in water depth leads to an increase in hydrostatic pressure on the surface of the overlayer. The greater the water depth, the larger the deformation of soils.

Figure 14 shows the well's deformation with GH dissociation at different water depths. The whole well moves toward the toe with the expansion of the dissociation zone at a water depth of $500 \mathrm{~m}$. As the water depth increases to 1000 and $1500 \mathrm{~m}$, an obvious inclination occurs with the expansion of the dissociation zone. The upper part of the well moves toward the top of the slope in the overlayer, while the lower part moves toward to the toe of the slope in the GH layer. The hydrostatic pressure at the surface of the overlayer constrains the horizontal deformation of the soil stratum and wells while increasing the settlement of soils. Hence, the deformation of a well is much different from that without water pressure.

\section{Conclusions}

Responses of the soil stratum and vertical wells to GH dissociation were studied using FLAC3D software, and the 

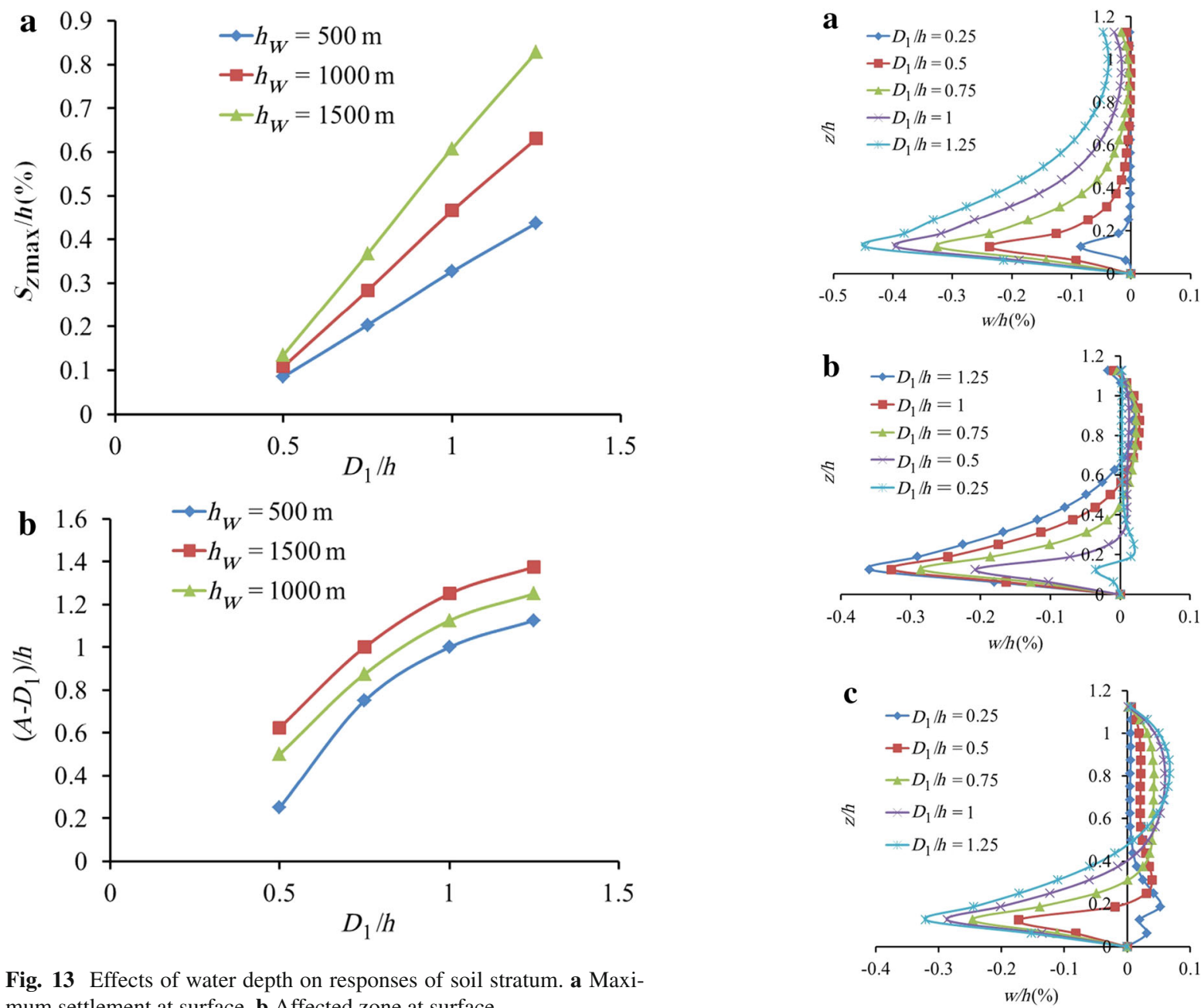

Fig. 13 Effects of water depth on responses of soil stratum. a Maximum settlement at surface. b Affected zone at surface

geological and geotechnical conditions in the South China Sea were used as references to set up a numerical model. The effects of the length of the GH dissociation zone, modulus, internal friction angle, cohesion, and thickness of the GH layer on the displacement of the soil stratum and wells were analyzed. The main conclusions drawn are as follows:

(1) The relative affected zone in the overlayer expands with an increase in the dissociation zone while remaining almost constant after the thickness of the dissociation zone becomes twice that of the overlayer. Maximum settlement occurs at the surface of the GH dissociation zone and is in an approximately linear increase with the expansion of the GH dissociation zone. The maximum horizontal displacement of the soil stratum occurs at the interface between the GH layer and the overlayer.

(2) The deformation of the soil stratum and wells increases with decreases in the modulus following GH dissociation. The settlement of the soil stratum increases nonlinearly as the thickness of the GH layer increases. The length of the affected zone is approximately linear

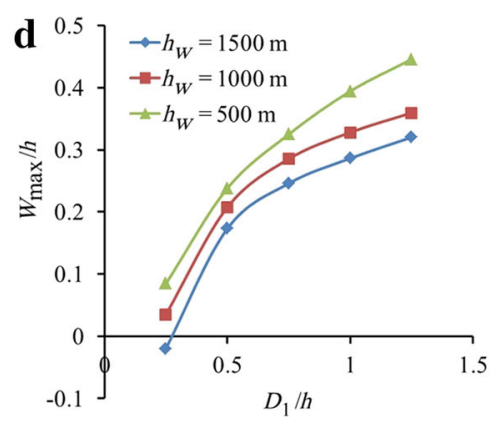

Fig. 14 Well deformation at different water depths. a $h_{w}=500 \mathrm{~m}$. b $h_{w}=1000 \mathrm{~m}$. c $h_{w}=1500 \mathrm{~m}$. d Maximum deformation of well at $z / h=1 / 8$

to its thickness. The soil deformation and the length of the affected zone increase with decreases in the internal friction angle owing to the development of a plastic failure zone.

(3) The interaction between two wells is negligible when the length of the dissociation zone around each well is less than one-fourth the distance between the wells and the affected zones are independent, while the interaction 
becomes significant when the length of the dissociation zone is over one-half the distance between the two wells owing to the connection of the affected zones.

(4) Different water depths lead to different hydrostatic pressures on the surface of the overlayer. Both the settlement and the affected zone increase with water depth, while the hydrostatic pressure constrains the horizontal displacement of the soil stratum and wells. The deformation of the soil stratum and wells is much different from that without water depth.

It is hoped that the results presented here will provide a reference for $\mathrm{GH}$ exploitation engineering in $\mathrm{GH}$ layers or gas exploitation under GH layers.

Acknowledgments This project was supported by the National Natural Science Foundation of China (Grants 11272314, 51239010, 41376078), a joint project of the Chinese National Petroleum Corporation and the Chinese Academy of Sciences (Grant 2015A-4813), and a project of the China Geological Survey (Grant GZH201100311).

\section{References}

1. Sloan, E.D.: Clathrate Hydrates of Natural Gases. Marcel Dekker Inc., New York (1998)

2. Riedel, M., Bellefleur, G., Dallimore, S.R., et al.: Amplitude and frequency anomalies in regional $3 \mathrm{D}$ seismic data surrounding the Mallik 5L-38 research site, Mackenzie Delta, Northwest Territories, Canada. Geophysics 71, 183-191 (2006)

3. Sakamoto, Y., Komai, T., Kawamura, T., et al.: Field scale simulation for the effect of relative permeability on dissociation and gas production behavior during depressurization process of methane hydrate in marine sediments. In: Proceedings of the ISOPE Ocean Mining Symposium, Lisben, Portugal (2007)

4. Sakamoto, Y., Kakumoto, M., Miyazaki, K., et al.: Numerical study on dissociation of methane hydrate and gas production behavior in laboratory scale experiments for depressurization: numerical study on estimation of permeability in methane hydrate reservoir. Int. J. Offshore Polar Eng. 19, 124-134 (2009)

5. Dickens, G.R., Quinby-Hunt, M.S.: Methane hydrate stability in seawater. Geophys. Res. Lett. 21, 2115-2118 (1994)

6. Milkov, A.V.: Worldwide distribution of submarine mud volcanoes and associated gas hydrates. Mar. Geol. 167, 29-42 (2000)

7. William, J.W., Ingo, A.P., William, F.W., et al.: Physical properties and rock physics models of sediment containing natural and laboratory-formed methane NGH. J. Am. Miner. 89, 1221-1227 (2004)
8. Xu, W., Germanovich, L.N.: Excess pore pressure resulting from methane hydrate dissociation in marine sediments: A theoretical approach. J. Geophys. Res. 111, B011104 (2006). doi:10.1029/ 2004JB003600

9. Lu, X.B., Wang, L., Wang, S.Y. et al.: Instability of seabed and wells induced by NGH dissociation. In: Proceedings of the 20th International Offshore and Polar Engineering Conference, Beijing, 110-114 (2010)

10. Zhang, X.H., Lu, X.B., Li, Q.P.: Formation of layered fracture and outburst during gas hydrate dissociation. J. Pet. Eng. Sci. 76, 212$216(2011)$

11. Hovland, M., Orange, D., Bjorkum, P. A. et al.: NGH and seepseffects on slope stability. In: Proceedings of the 11th International Offshore and Polar Engineering Conference, Norway, 471-476 (2001)

12. Locat, J., Lee, H.: Submarine landslide, advances and challenges. J. Can. Geotech. 39, 193-212 (2002)

13. Kayer, R.E., Lee, H.J.: Pleistocene slope instability of NGH-laden sediment on the Beaufort Sea Margin. J. Mar. Geotechnol. 10, 125141 (1991)

14. Sultan, N., Cochonat, P., Foucher, J.P., et al.: Effect of NGHs melting on seafloor slope instability. J. Mar. Geol. 213, 379-401 (2004)

15. Gilles, G., David, G., Aaleksandr, M.: Characterization of in situ elastic properties of NGH bearing sediments on the Blake Ridge. J. Geophys. Res. 104, 17781-17795 (1999)

16. Sassoon, D.: Did Deep water methane hydrates cause the BP gulf explosion? http://www.guardian.co.uk/environment/2010/ may/20/deepwater-methane-hydrates-bp-gulf (2010)

17. Wang, S.Y., Zheng, W., Lu, X.B.: The effects of gas hydrate dissociation on the stability of pipeline in seabed. In: Proceedings of the 19th International Offshore and Polar Engineering Conference, Japan, 49-53 (2009)

18. Cai, G.-Q., Zhao, C.-G., Sheng, D.-C., et al.: Formulation of thermo-hydro-mechanical coupling behavior of unsaturated soils based on hybrid mixture theory. Acta Mech. Sin. 30, 559-568 (2014)

19. Sultan, N., Cochonat, P., Canals, M., et al.: Triggering mechanisms of slope instability processes and sediment failures on continental margins: a geotechnical approach. Mar. Geol. 213, 291-321 (2004)

20. Iwai, H., Kimoto, S., Akaki, T., et al.: Stability analysis of methane hydrate bearing soils considering dissociation. Energies 8, 5381$5412(2015)$

21. Zhang, X.H., Lu, X.B., Zheng, Z.M., et al.: Heat-Induced evolution of phase transformations in tetrahydrofuran hydrate-bearing sediment. J. Heat Transf. 136, 052002 (2014)

22. Chen, X.D., Zhang, X.H., Liu, H.J., et al.: Numerical study on soil instability due to gas hydrate dissociation in sediments. In: The Chinese Congress of Theoretical and Applied Mechanics (CCTAM), 15-18 August (2015)

23. Zhang, X.H., Lu, X.B., Shi, Y.H., et al.: Study on the mechanical properties of hydrate-bearing silty clay. Mar. Pet. Geol. 67, 72-80 (2015) 